\title{
The Relationship of Parental Knowledge to the Development of Extremely Low Birth Weight Infants
}

\author{
MARGO DICHTELMILLER \\ SAMUEL J. MEISELS \\ JAMES W. PLUNKETT \\ MARY ELLEN A. BOZYNSKI \\ CAROL CLAFLIN \\ SARAH C. MANGELSDORF
}

The University of Michigan

This study examined the relationship between parental experience, parental knowledge, and the development of extremely low birth weight infants. The subjects $(\mathrm{N}=40)$ were extremely high-risk infants averaging 1000.0 grams birthweight and 28.1 weeks gestational age. The study found that mothers of preterm infants called upon the same types of experiences and sources of information about infancy as mothers of full-term infants. Further, ratings of maternal accuracy on the Knowledge of Infant Development Inventory accounted for $13 \%$ to $15 \%$ of the variation on the Mental Development Index (MDI) and Psychomotor Development Index (PDI) of the Bayley Scales of Infant Development at 8 months corrected age. The infants of mothers with greater than average knowledge about infancy scored approximately one standard deviation higher on both the MDI and the PDI than did the infants of mothers who had less than average knowledge about infancy. Implications for intervention are discussed.

\section{THE RELATIONSHIP OF PARENTAL KNOWLEDGE TO THE DEVELOPMENT OF EXTREMELY LOW BIRTHWEIGHT INFANTS}

Researchers have devoted extensive study to understanding the developmental sequelae of preterm birth, although they have not reached consensus regarding the etiology of negative outcomes (Meisels \& Plunkett, 1988). Some researchers have focused on biological sources of developmental problems (Field, Dempsey, \& Shuman, 1983; Meisels, Plunkett, Roloff, Pasick, \& Stiefel, 1986; Siegel, 1982, 1983), whereas others have studied the quality of parent-infant interaction as a possible reason for the nonoptimal development of preterm infants (Crnic, Greenberg, Ragozin, Robinson, \& Basham, 1983; Field, 1977, 1979; Goldberg, 1979; Minde, Marton, Manning, \& Hines, 1980). Still another area of investigation, although one that has received relatively little attention, concerns parents' understanding of how to meet their preterm infants' needs, as well as parental anxiety about caring successfully for a sick child (Rauh, Nurcombe, Ruoff, Jette, \& Howell, 1982). This study was designed to investigate the relationship between parental knowledge of infancy and pre- 
term infants' mental and psychomotor competence in the first year of life.

Parental knowledge is an aspect of adult social cognition that comprises one's understanding of child development processes, caregiving and childrearing skills, and developmental norms. Many terms have been used to describe cognition about parenting. Goodnow (1984) prefers the general term "ideas" to describe these cognitions, whereas others refer to "internal referents" (Hess, Kashigawi, Azuma, Price, E Dickson, 1980); "beliefs" (McGillicuddy-DeLisi, 1980); "belief systems" (Sigel, 1985); "developmental models" (Sameroff, 1975); and "naive theory" (Ninio, 1979). The variety of labels reflects the underlying diversity in which parental knowledge has been conceptualized and studied.

Some researchers have focused on the specific content of parents' knowledge. MacPhee (1983, 1984), for example, focused quite narrowly on knowledge, concentrating on facts, norms, information, and principles that provide the parent with descriptive information and with an understanding of the mechanisms or processes of development. Researchers interested in the relationship between parental knowledge and parental actions or child outcomes have often assessed parents' expectations of their child's development, including their knowledge of normal developmental milestones (De Lissovoy, 1973; Field, Widmayer, Stringer, E Ignatoff, 1980; Goodnow, 1984; MacPhee, 1983; Schilmoeller $\varepsilon$ Baranowski, 1985; Stevens, 1984). These researchers chose to study developmental timetables because of their influence on parents' evaluations of their child, and thus on parental actions (Heckhausen, 1987). Studies have demonstrated that unrealistic developmental expectations may result in asynchrony between mother and infant (Schilmoeller $\varepsilon$ Baranowski, 1985). Expectations that are too high may leave the child frustrated (Hunt $\varepsilon$ Paraskevopoulos, 1980), thus increasing the likelihood of punitive behavior on the part of the parent, whereas low expectations may result in insufficient stimulation of the infant (Ninio, 1979).

Research about the determinants of parental knowledge shows that experiences as both a child and as a parent influence parents' theories of how children behave and develop. Demographic characteristics, such as socioeconomic status (Hess et al., 1980; McGillicuddy-DeLisi, 1984; Sameroff, 1975; Sameroff $\&$ Feil, 1985), cultural background (Gutierrez, Sameroff, $\mathcal{E}$ Karrer, 1988; Hess et al., 1980; Ninio, 1979), age (De Lissovoy, 1973; Field et al., 1980; Stevens, 1984), and education (Bee et al., 1982; McGillicuddy-De Lisi, 1984 ) influence the types of experiences one is likely to have, as well as the integration of those experiences. During parenthood, the family constellation (McGillicuddy-DeLisi, 1984) and the need to respond to the child pragmatically (Goodnow, 1984) also frequently affect parents' beliefs.

While the demographic research demonstrates that a parent's experiences affect parental knowledge, MacPhee's (1981) research delves further into the different aspects of experience itself. According to MacPhee, experience has two dimensions. The first dimension, formality, refers to the qualifications of the information source. Formal experience is gathered from experts in academic or professional settings and includes high school and college classes in child development, parenting education courses, and professional work with children. Informal experience arises from participating in such activities as babysitting, talking with relatives and interacting with siblings. The second dimension relates to how information is attained, either through direct observation of children or vicariously through sociocultural experiences. Direct observational experiences arise during hands-on contact with children, such as parenting and babysitting. In these and other direct experi- 
ence situations, parents draw their own conclusions about how children behave from their own observations. On the other hand, sociocultural experiences occur outside of hands-on experience with children. The parent is exposed to others' ideas and opinions about children through reading books and magazines, listening to media presentations about child development, talking with a pediatrician or discussing childrearing issues with friends and family.

In a study of 256 mothers of 6-month-old infants, MacPhee (1983) attempted to discover the kinds of experience contributing to maternal knowledge of infant development. The most valued information sources among all the mothers were the sociocultural experiences that came from books, other parents, relatives, and pediatricians. Mothers of lower socioeconomic status cited informal experiences within the family such as talking with relatives and babysitting siblings more frequently, whereas middle-class mothers relied on formal experiences requiring higher education. Accurate information about infant development was correlated with the amount of formal experience, such as college classes in child psychology and reading about child care and development. Parity and other items that indicated direct, hands-on experiences with infants were not associated with accuracy of knowledge. Although these results are counterintuitive, MacPhee has repeatedly found the same statistically nonsignificant relationship between direct experiences with children and accurate knowledge (MacPhee, 1984), concluding that "sociocultural influences appear to shape knowledge more powerfully than do direct observational experiences" (MacPhee, 1983, p. 6).

In short, several factors have been associated consistently with the amount of parental knowledge or the particular nature of parental beliefs. Some of these factors are difficult or impossible to alter, such as the parent's child- hood experiences, age, educational level, socioeconomic status, and cultural background. However, knowledge about these factors may enable us to make some general statements about a parent's knowledge level or belief system. Furthermore, specific knowledge about parenting, beliefs governing interactions with children, and the level of formal exposure to information about child development can be altered. Changes in these areas may provide a means of enhancing child development.

Overall, many studies exemplifying different conceptions of parental knowledge and different approaches to uncovering the relationship between knowledge and child outcomes have reached the same conclusion: differential levels of parental knowledge make a small but significant contribution to the child's development (Hess et al., 1980; Hunt E Paraskevopoulos, 1980; McGillicuddyDeLisi, 1985; Sigel, 1984). Only one study (Field et al., 1980) presented contradictory findings. However, the authors suggested that unmeasured variables relating to the nature of the home environment accounted for the results they obtained. Findings regarding the contribution of parental knowledge to children's development provide support for intervention efforts directed at educating parents. Certainly, in light of the consistency of these findings, changing parental knowledge and beliefs represents a potentially important means of improving developmental outcomes for high-risk and developmentally vulnerable infants.

This study had two purposes. The first was to investigate the relationship between experience and parental knowledge in a sample of parents of extremely low birth weight infants. Two questions were posed: Do mothers of preterm infants refer to the same sources of information as do parents of full-term infants, and do different types of experiences and different demographic characteristics influence 
the accuracy of mothers' knowledge about infancy? The second purpose of the study was to determine whether parental knowledge relates to child outcomes in a sample of parents of extremely low birth weight infants, as it does in studies of parents of healthy fullterm children.

\section{METHOD}

\section{Subjects}

Data are presented from 40 preterm infants who were enrolled in a longitudinal study of the cognitive, motoric, socio-emotional, medical, and neurologic sequelae of extremely low birth weight. Preterm infants meeting the weight criterion $(<1250 \mathrm{~g})$, living within a 50mile radius of the research center, and admitted to the neonatal intensive care unit within the first 72 hours of life, were eligible for enrollment. The study excluded infants with the following medical conditions: severe retrolental fibroplasia, multiple congenital anomalies or syndromes, bilateral severe sensorineural hearing loss, microcephaly, congenital TORCH infections, and severe intrauterine growth retardation. In addition, infants with mothers who were drug-addicted or younger than 17 years of age, and infants discharged to foster care, were excluded.

The infants were born between April 1, 1986 and April 15, 1988, and were identified from consecutive admissions to a large midwestern university hospital. From 153 admissions, 44 (29\%) expired, leaving 109 infants. An additional 42 infants did not meet the eligibility criteria: 22 lived more than 50 miles from the hospital, and 20 had at least one of the excluded medical conditions. Therefore, 67 surviving infants met the criteria and were available for enrollment. Of these infants, 1 expired subsequent to discharge, the parents of 8 refused to participate, and 1 was discharged before the family was invited to participate. The final preterm sample consisted of 57 in- fants. Due to changes in experimental protocol, only 49 of the original 57 families received the questionnaire. Eight questionnaires were not returned. When the infants were 8 months corrected age, they were evaluated with the Bayley Scales of Infant Development (Bayley, 1969). One subject was not able to be evaluated at 8 months, leaving 40 dyads to participate in this study.

Perinatal characteristics of the subjects are presented in Table 1. Demographic characteristics of the sample are presented in Table 2.

\section{Procedure}

At the time of the infants' discharge from the hospital, the mothers completed the Knowledge of Infant Development Inventory (KIDI) (MacPhee, 1981) and the Catalog of Previous Experience with Infants (COPE) (MacPhee, 1981) as part of a longer questionnaire. The KIDI, written at a 6 th- to 7 th-grade reading level, measures three areas of parental knowledge: childrearing practices, developmental processes, and infant norms. It samples physical, social, linguistic, perceptual, and cognitive domains of infant development and includes items concerning early experience and learning, the bidirectionality of social influences, atypical development, individual differences, and health and safety practices. The 75 items can be grouped into the following

Table 1

\section{Perintal Characteristics}

\begin{tabular}{lrrc}
\hline Variable & $M$ & (SD) & Range \\
\hline $\begin{array}{l}\text { Birthweight } \\
\text { (grams) }\end{array}$ & 1000.0 & $(189.1)$ & $560-1250$ \\
$\begin{array}{l}\text { Gestational age } \\
\text { (weeks) }\end{array}$ & 28.1 & $(1.9)$ & $24-32$ \\
$\begin{array}{l}\text { Hospitalization } \\
\text { (days) }\end{array}$ & 93.8 & $(61.4)$ & $33-346$ \\
Apgar at 1 minute & 4.6 & $(2.0)$ & $1-8$ \\
Apgar at 5 minutes & 6.7 & $(1.6)$ & $2-9$ \\
\hline
\end{tabular}

Note. $N=40$. 
TABLE 2

Demographic Characteristics

\begin{tabular}{lrrr}
\hline Variable & M & (SD) & $\%$ \\
\hline Maternal Age (years) & 27.7 & $(5.3)$ & \\
Number of Children & 2.1 & $(1.0)$ & \\
Maternal Education (years) & 13.8 & $(2.0)$ & \\
Hollingshead Score & 38.7 & $(14.0)$ & \\
Race (Caucasian) & & & 90.0 \\
Marital Status (married) & & & 82.5 \\
Maternal Education & & & \\
$\quad$ High School & & & 7.5 \\
$\quad$ High School Graduate & & 27.5 \\
Some College & & 47.5 \\
$\quad$ College graduate & & 17.5 \\
Hollingshead Classification & & & \\
$\quad$ Class 1 & & 17.5 \\
Class 2 & & 40.0 \\
$\quad$ Class 3 & & 10.0 \\
Class 4 & & 20.0 \\
$\quad$ Class 5 & & 12.5 \\
Sex of child (male) & & 50.0 \\
\hline No. $N=40$. & &
\end{tabular}

Note. $N=40$.

four subscales: norms and milestones, developmental principles, parenting skills, and health and safety knowledge.

Each of the KIDI items is scored by the parent as "right" $(+1)$, "wrong" $(-1)$, or "not sure" (0). The KIDI accuracy summary score is calculated by dividing the number of items correct by the number of items attempted. One item of the KIDI, "Most premature babies end up being abused, neglected, or mentally retarded," was deleted for use with this sample of parents of premature infants.

The KIDI was standardized on 226 mothers who represented a broad spectrum of socioeconomic levels, from those with a 7th-grade education and no income to working professionals. The average maternal age was 26 years; $59 \%$ were Caucasian. Half of the mothers had more than one child, and $77 \%$ were married. The alpha coefficient was .82 for the mothers, indicating the internal consistency of the multi-item scale. The Guttman split- half reliability was .85 . The two-week retest coefficient was $r=.92$ for the total score, $r=.91$ for the accuracy summary score. The average accuracy summary score was .80 . Questionnaires were distributed by mail; $85 \%$ were returned.

The COPE is a 17 -item survey providing descriptive information about exposure to information about infants and about experience with infants. The first section evaluates the amount of exposure to babies. The second section assesses the importance of various sources of knowledge about infancy. The last item, "Overall, how much do you think you know about infants?" asks the parent to evaluate her confidence in her knowledge of infants. The responses for each item are scored such that a low number indicates a low level of experience or importance, and a high number indicates a high level.

At 8 months corrected age, 39 infants returned to the research center and were evaluated on the Bayley Scales of Infant Development (Bayley, 1969). One infant was evaluated in the hospital with his mother present. The Bayley Scales of Infant Development results in two scores, the Mental Development Index (MDI) and the Psychomotor Development Index (PDI).

\section{RESULTS}

The first purpose of this research was to investigate the relationship between experience and parental knowledge. The mean ratings of the COPE items are presented in Table 3. In this sample, having primary parenting responsibility for an infant, babysitting when younger, talking with medical professionals, having confidence in one's knowledge about infancy, talking with family, and reading books and magazines had the highest mean values. Although parents of preterm infants placed greater emphasis on early babysitting experience and overall confidence, the other four items were 
TABLE 3

COPE Item Means, Standard Deviations, and Ranges

\begin{tabular}{|c|c|c|c|}
\hline COPE Items & $M$ & $(S D)$ & Range \\
\hline $\begin{array}{l}\text { Primary parenting } \\
\text { responsibility for } \\
\text { infant }\end{array}$ & 3.7 & $(1.4)$ & $1-5$ \\
\hline $\begin{array}{l}\text { Babysitting when } \\
\text { younger }\end{array}$ & 3.5 & (.8) & $1-4$ \\
\hline $\begin{array}{l}\text { Talking with } \\
\text { doctors/psychologists }\end{array}$ & 3.3 & (.7) & $2-4$ \\
\hline Overall confidence & 3.1 & (.5) & $2-4$ \\
\hline Talking with family & 3.0 & (.9) & $1-4$ \\
\hline $\begin{array}{l}\text { Reading books and } \\
\text { magazines }\end{array}$ & 3.0 & (.9) & $1-4$ \\
\hline $\begin{array}{l}\text { Talking with friends with } \\
\text { babies }\end{array}$ & 2.9 & (1.0) & $1-4$ \\
\hline $\begin{array}{l}\text { Watch infants and } \\
\text { parents when younger }\end{array}$ & 2.5 & $(.9)$ & $1-4$ \\
\hline Sibling care & 2.2 & (1.3) & $1-4$ \\
\hline Talking with spouse & 2.1 & (1.0) & $1-4$ \\
\hline $\begin{array}{l}\text { Comparing your baby } \\
\text { with others }\end{array}$ & 1.9 & $(1.0)$ & $1-4$ \\
\hline $\begin{array}{l}\text { Learning from mass } \\
\text { media }\end{array}$ & 1.9 & (.9) & $1-4$ \\
\hline $\begin{array}{l}\text { Informal babysitting } \\
\text { (own child present) }\end{array}$ & 1.9 & (1.2) & $1-4$ \\
\hline $\begin{array}{l}\text { Child care or parenting } \\
\text { class }\end{array}$ & 1.5 & (.7) & $1-3$ \\
\hline $\begin{array}{l}\text { Work in a professional } \\
\text { setting with infants }\end{array}$ & 1.4 & $(1.0)$ & $1-5$ \\
\hline $\begin{array}{l}\text { Work in a } \\
\text { nursery/daycare center }\end{array}$ & 1.3 & (1.0) & $1-5$ \\
\hline $\begin{array}{l}\text { College class in child } \\
\text { development }\end{array}$ & 1.3 & (.5) & $1-3$ \\
\hline
\end{tabular}

Note. $N=40$.

the items most often referred to by parents of full-term infants in MacPhee's standardization sample.

In light of the small number of subjects, the 17 COPE items were factor analyzed, using a varimax factor analysis with rotated factors, to reduce them to a smaller set of variables. Factor scores were created by assigning weights of one to the salient loading variables and zero weights to nonsalient loadings on the factors. For a variable to be considered a salient loading variable, the loading had to be at least 10 greater than its loading on any other factor. Otherwise, the variable was omitted (Gorsuch, 1983). One item, talking with one's spouse, was not included in creating factor scores because it loaded almost equally on Factors 1 and 3 . The resulting factors account for $40.9 \%$ of the variance among the items. As seen in Table 4, three factors were derived from the COPE items. Sociocultural Experience (Factor 1), accounts for $17.95 \%$ of the total variance. Direct Experience (Factor 2 ), accounts for $12 \%$ of the total variance, and Early Experience (Factor 3), accounts for $11 \%$ of the variance. The three factors reflect the dimensions of experience identified by MacPhee (1981). Factors 1 and 2 relate to the manner in which information is learned. Factor 3 combines items related to the four aspects of experience: formal, informal, direct, and vicarious. In Factor 3, these different types of experience are united by their occurrence during childhood and adolescence.

The second question addressed whether different types of demographic characteristics and experiences influence maternal knowledge. Maternal accuracy scores on the KIDI ranged from .63 to .95 , with a mean of .84 . Maternal age was the only demographic variable that correlated significantly with maternal accuracy $(.34, p<.05)$. In addition, the relationship between accuracy and whether the mother had one child or more than one child approached significance $(.30, p=.06)$. A regression analysis was performed to determine how well the three COPE factors predicted the mother's accuracy on the KIDI. However, the COPE factors did not explain any variance in maternal accuracy. In this sample of high-risk infants, maternal age was the only demographic characteristic or experience associated with maternal accuracy.

The average MDI for this sample of infants 
TABLE 4

COPE Factor Structure

\begin{tabular}{|c|c|c|c|}
\hline COPE Items & $\begin{array}{l}\text { Factor } \\
1 \\
\text { Socio- } \\
\text { cultural } \\
\text { Experi- } \\
\text { ence }\end{array}$ & $\begin{array}{c}\text { Factor } \\
2 \\
\text { Direct } \\
\text { Experi- } \\
\text { ence }\end{array}$ & $\begin{array}{c}\text { Factor } \\
3 \\
\text { Early } \\
\text { Experi- } \\
\text { ence }\end{array}$ \\
\hline $\begin{array}{l}\text { Learning from mass } \\
\text { media }\end{array}$ & .4743 & - & - \\
\hline $\begin{array}{l}\text { Reading } \\
\text { magazines/books }\end{array}$ & 6404 & - & - \\
\hline Talking with family & .7675 & - & - \\
\hline $\begin{array}{l}\text { Talking with friends } \\
\text { with babies }\end{array}$ & .8027 & - & - \\
\hline $\begin{array}{l}\text { Comparing your } \\
\text { child to others }\end{array}$ & .6313 & - & - \\
\hline $\begin{array}{l}\text { Talking to } \\
\text { doctors/ } \\
\text { psychologists }\end{array}$ & .4596 & - & - \\
\hline $\begin{array}{l}\text { Child care/parenting } \\
\text { class }\end{array}$ & - & .5348 & - \\
\hline $\begin{array}{l}\text { Working in nursery } \\
\text { school/day care } \\
\text { center }\end{array}$ & - & .4928 & - \\
\hline $\begin{array}{l}\text { Working } \\
\text { professionally with } \\
\text { infants }\end{array}$ & - & .6755 & - \\
\hline $\begin{array}{l}\text { Primary parenting } \\
\text { responsibility of } \\
\text { infant }\end{array}$ & - & .4565 & - \\
\hline Informal babysitting & - & .4611 & - \\
\hline Overall confidence & - & .5311 & - \\
\hline $\begin{array}{l}\text { Sibling care } \\
\text { Babysitting when }\end{array}$ & - & - & .3189 \\
\hline & - & - & .4845 \\
\hline $\begin{array}{l}\text { College class in } \\
\text { psychology or child } \\
\text { development }\end{array}$ & - & - & -.6543 \\
\hline $\begin{array}{l}\text { Watching infants and } \\
\text { parents when } \\
\text { younger }\end{array}$ & - & - & .5860 \\
\hline Talking with spouse & - & - & -.3383 \\
\hline$\%$ of Total Variance & 18.0 & 12.0 & 11.0 \\
\hline
\end{tabular}

Note. $N=40$.

at 8 months corrected age was 93.9, with a standard deviation of 23.8; the average PDI was 89.5, with a standard deviation of 23.0. Six infants had MDIs and PDIs below 50. Because the conversion tables for determining the $\mathrm{MDI}$ and PDI do not include scores below 50 , these infants' scores were entered as 49. Correlations between a variety of demographic characteristics and MDI and PDI scores from the Bayley were examined. There were no significant relationships.

The influence of socioeconomic status on maternal accuracy and Bayley performance was explored. Most of the families (57.5\%) fell within the upper two classes (of five social strata) of the Hollingshead Four Factor Index of Social Status (Hollingshead, 1975). The correlation between the Hollingshead score and accuracy was not significant. Furthermore, when the sample was divided into high and low socioeconomic status (Hollingshead strata one, two, and three compared with strata four and five), the mean MDIs and PDIs of the two groups were not significantly different. Therefore, socioeconomic status did not influence accuracy of the mothers' knowledge about infancy.

In order to understand the relationship between parental knowledge and the infant's development, Pearson product moment correlations were computed between mothers' accuracy scores on the KIDI, and the infants' Bayley scores. Maternal accuracy correlated .36 with the $\mathrm{MDI}(p<.05)$ and .39 with the PDI $(p<.01)$. Two regression analyses were also conducted (see Table 5). Maternal accuracy accounted for $12.9 \%$ of the variance in the

TABLE 5

Regression Statistics for Equations Predicting Mental Development (MDI) and Psychomomtor Development (PDI)

\begin{tabular}{llllcl}
\hline Criterion & Predictor & $R$ & $R^{2}$ & $f(d f)$ & $P$ \\
\hline Bayley MDI & Accuracy & .36 & .13 & $5.63(1,39)$ & .02 \\
Bayley PDI & Accuracy & .39 & .15 & $6.85(1,39)$ & .01 \\
\hline Note. $N=40$.
\end{tabular}


Bayley $\mathrm{MDl}$. The regression equation was significant, $F(1,39)=5.63, p=.02$. Similarly, maternal accuracy accounted for $15.3 \%$ of the variance in the Bayley $\mathrm{PDI}, F(1,39)=6.85$, $p=.01$. When the three COPE factors were added to the regression equations, they did not explain any additional variance on the Mental or Psychomotor scales of the Bayley.

To analyze these data further, the mothers were divided into two groups based on their accuracy scores. Mothers who scored above the mean had infants with an average $\mathrm{MDI}$ of 100.3, while parents who scored below the mean had infants whose average $\mathrm{MDI}$ was 86.8. Although this difference of 13.5 points only approaches statistical significance $(p=$ .07 ), it represents nearly one standard deviation difference in performance on the Bayley. Parents who scored above the mean had infants with a mean PDI of 96.6, while parents who scored below the mean had infants whose average PDI was $81.5(p=.03)$, a full standard deviation difference. Therefore, maternal accuracy is related to child performance on the Bayley at 8 months corrected age.

\section{DISCUSSION}

The first research question concerned the relationship between parental experience and knowledge about infancy. The COPE items with the highest mean values were the following: having primary parenting responsibility for an infant, babysitting when younger, talking with physicians and psychologists, overall confidence, talking with family, reading books and magazines about infancy, and talking to friends who have babies. With the exception of babysitting as a teenager and overall confidence, these are the same items with the highest means in MacPhee's (1984) sample of mothers of full-term infants. It appears that both parents of preterm infants and parents of full-term infants cite the same sources for their knowledge of infancy and rely largely on sociocultural sources for information about infants. The most important source of knowledge - having primary responsibility for parenting an infant-highlights the fact that parents learn from ongoing experiences with their own infant in which they are forced to make immediate decisions without reference to outside assistance.

The three COPE factors, Sociocultural Exposure, Direct Experience, and Early Experience, illustrate MacPhee's (1981) two dimensions of experience. Factor 1, Sociocultural Exposure, includes a combination of formal and informal items linked together by their vicarious nature. The parent learns about infancy second hand, through talking with relatives, friends, and the pediatrician, and through books, magazines and other mass media, rather than through direct, observational experiences. Factor 2 combines the direct, hands-on experience items. Overall confidence also loaded on this factor and perhaps indicated that the mother's confidence is linked to experiences that allow her to construct her own knowledge. Factor 3, Early Experience, includes early, hands-on experiences with infants and two negatively loading variableshaving taken a college class in child development and talking with one's spouse. The juxtaposition within Factor 3 of items representing early exposure to infants and two negatively loading items pertaining to adult experience (taking a college level course in child development, talking with one's spouse) suggests that knowledge attained as an adult may require change in previously held ideas about infancy.

Although the factor analysis of COPE items resulted in three interpretable factors, it did not explain the variance in maternal accuracy scores on the KIDI. This finding corroborates research by MacPhee (1981), who also found few positive relationships between COPE factors and performance on the KIDI. Among the demographic characteristics, only mater- 
nal age related to maternal accuracy, with older mothers scoring higher on the KIDI; parity also approached significance with maternal accuracy. While mothers with more than one child were more accurate on the KIDI, the number of children did not correlate significantly with accuracy. It appears that, on this scale, the mother learns all she is going to learn from her first child. This finding is congruent with other research regarding parity and parental knowledge (MacPhee, 1981). Overall, it appears that the experience factors and the demographic variables tapped in this study do not provide insight regarding the origins of maternal knowledge about infancy.

Although other researchers consistently have found a significant relationship between socioeconomic status and parental knowledge in full-term populations (McGillicuddyDeLisi, 1984; MacPhee, 1981), no such relationship was found in this sample of extremely low birthweight infants. Maternal accuracy was not significantly correlated with any measure of socioeconomic status, nor did socioeconomic status explain any variance in $\mathrm{MDI}$ and PDI. These nonsignificant relationships may be due to the relatively greater role biological status played in this sample of very high-risk infants. The fact that all of the infants in this sample had respiratory distress syndrome and $55 \%$ had bronchopulmonary dysplasia may have outweighed the impact of socioeconomic status, especially at 8 months corrected age.

The second major research question concerned whether the mothers' accuracy on the KIDI was associated with how well their children performed on the Bayley Scales of Infant Development at 8 months corrected age. In this sample of very low birth weight babies, mothers' knowledge accounted for approximately $13 \%$ and $15 \%$ of variation on the MDI and PDI, respectively. Although $85 \%$ to $87 \%$ of the variance in Bayley scores remains unaccounted for, this result is very important for two reasons. First, it replicates previous findings of a small, but significant effect of parental knowledge on child development and extends them to a sample of extremely low birth weight infants. Second, it provides support for the establishment of parent education programs by demonstrating that intervention efforts aimed at increasing parents' knowledge have the potential to improve outcomes for premature infants. The difference in cognitive and motor performance between infants whose mothers demonstrated above average knowledge about infancy represented approximately one standard deviation, a difference that is both statistically significant and educationally important.

Future research should focus on other aspects of parental knowledge and beliefs among parents of low birth weight infants. To the extent that investigators are able to determine the aspects of parental knowledge that influence child outcomes, practitioners will be able to focus on parents more effectively in their intervention programs.

\section{REFERENCES}

Bayley, N. (1969). Bayley Scales of Infant Development. New York: Psychological Corp.

Bee, H.L., Barnard, K.E., Eyres, S.J., Gray, C.A., Hammond, M.A., Spietz, A.L., Snyder, C., \& Clark, B. (1982). Prediction of IQ and language skill from perinatal status, child performance, family characteristics, and mother-infant interaction. Child Development, 53, 1134-1156.

Crnic, K.A., Greenberg, M.T., Ragozin, A.S., Robinson, N.M., \& Basham, R.B. (1983). Effects of stress and social support on mothers and premature and full-term infants. Child Development, 54, 209-217.

De Lissovoy, V. (1973). Child care by adolescent parents. Children Today, 2, 22-25.

Field, T.M. (1977). Effects of early separation, interactive deficits, and experimental manipulations on infant-mother face-to-face interaction. Child Development, 48, 763-771. 
Field, T.M. (1979). Interaction patterns of preterm and full-term infants. In T. Field, A.M. Sostek, S. Goldberg, \& H.H. Shuman (Eds.), Infants born at risk (pp. 333-357). Jamaica, NY: Spectrum.

Field, T.M., Dempsey, J.R., \& Shuman, H.H. (1983). Five year follow-up of preterm respiratory distress syndrome and post-term postmaturity syndrome infants. In T. Field $\& A$. Sostek (Eds.), Infants born at risk (pp. 317-336). Jamaica, NY: Spectrum.

Field, T.M., Widmayer, S.M., Stringer, S., \& Ignatoff, E. (1980). Teenage, lower-class, black mothers and their preterm infants: An intervention and developmental follow-up. Child Development, 51, 426-436.

Goldberg, S. (1979). Premature birth: Consequences for the parent-infant relationship. American Scientist, 67, 214-220.

Goodnow, JJ. (1984). Parents' ideas about parenting and development: $A$ review of issues and recent work. In M.E. Lamb, A.L. Brown, \& B. Rogoff (Eds.), Advances In Developmental Psychology, (Vol. 3, pp. 193-242). Hillsdale, N.J.: Lawrence Erlbaum.

Gorsuch, R.L. (1983). Factor analysis. Hillsdale, NU: Lawrence Erlbaum.

Gutierrez, J., Sameroff, A.., \& Karrer, B.M. (1988). Acculturation and SES effects on MexicanAmerican parents' concepts of development. Child Development, 59, 250-255.

Heckhausen, J. (1987). How do mothers know? Infants' chronological age or infants' performance as determinants of adaptation in maternal instruction. Journal of Experimental Child Psychology, 43, 212-226.

Hess, R.D., Kashiwagi, K., Azuma, H., Price, G.G., $\mathcal{E}$ Dickson, W.P. (1980). Maternal expectations for mastery of developmental tasks in Japan and the United States. International Journal of Psychology, 15, 259-271.

Hollingshead, A. (1975). Four factor index of social status. Unpublished paper, Department of Sociology, Yale University, New Haven, CT.

Hunt, J. McV., \& Paraskevopoulos, J. (1980). Children's psychological development as a function of the inaccuracy of their mothers' knowledge of their abilities. Journal of Genetic Psychology, 136, 285-298.
MacPhee, D. (1981). Knowledge of Infant Development Inventory. Unpublished questionnaire and manual, University of North Carolina, Department of Psychology, Chapel Hill, NC.

MacPhee, D. (1983, April). The nature of parents' experiences with and knowledge about infant development. In I. Sigel (Chair), The cognitive experience of parents: The study and implications of parental knowledge, perceptions, reasoning, and beliefs. Symposium conducted at the biennial meeting of the Society for Research on Child Development, Detroit.

MacPhee, D. (1984, March). Mothers' acquisition and reconstruction of knowledge about infancy. Paper presented at the biennial meeting of the Southwestern Society for Research in Human Development, Denver.

McGillicuddy-DeLisi, A.V. (1980). The role of parental beliefs in the family as a system of mutual influences. Family Relations, 29, 317-323.

McGillicuddy-DeLisi, A.V. (1984). The relationship between parents' beliefs about development and family constellation, socioeconomic status, and parents' teaching strategies. In M.E. Lamb, A.V. Brown, \& B. Rogoff (Eds.), Advances in Developmental Psychology, (Vol. 3, pp. 261-299). Hillsdale, NJ: Lawrence Erlbaum.

McGillicuddy-De Lisi, A.V. (1985). The relationship between parental beliefs and children's cognitive level. In I.E. Sigel (Ed.), Parental belief systems: Psychological consequences for children (pp. 7-24). Hillsdale, NJ: Lawrence Erlbaum.

Meisels, S.J., \& Plunkett, J.W. (1988). Developmental consequences of preterm birth: Are there long-term effects? In P.B. Baltes, K.L. Featherman, \& R.M. Lerner (Eds.), Life-span Development and Behavior, (Vol. 9, pp. 87-128). Hillsdale, NJ: Lawrence Erlbaum.

Meisels, S.J., Plunkett, J.W., Roloff, D.W., Pasick, P.L., \& Steifel, G.S. (1986). Growth and development of preterm infants with respiratory distress syndrome and bronchopulmonary dysplasia. Pediatrics, 77, 345-352.

Minde, K.K., Marton, P., Manning, D., \& Hines, B. (1980). Some determinants of mother-infant interaction in the premature nursery. Journal 
of the American Academy of Child Psychiatry, 19, 1-21.

Ninio, A. (1979). The naive theory of the infant and other maternal attitudes in two subgroups in Israel. Child Development, 50, 976-980.

Rauh, V.A., Nurcombe, B., Ruoff. P., Jette, A. $\varepsilon$ Howell, C.T. (1982). The Vermont Infant Studies Project: The rationale for a motherinfant transaction program. In L.A. Bond $\varepsilon$ J.M. Joffe (Eds.), Facilitating infant and early childhood development (pp. 258-280). Hanover, NH: University Press of New England.

Sameroff, AJ. (1975). Early influences on development: Fact or fancy? Merrill-Palmer Quarterly, 21, 267-294.

Sameroff, A.J., \& Feil, L.A. (1985). Parental concepts of development. In I.E. Sigel (Ed.), Parental belief systems: Psychological consequences for children (pp. 83-105). Hillsdale, NJ: Lawrence Erlbaum.

Schilmoeller, G.L., \& Baranowski, M.D. (1985). Childrearing of firstborns by adolescent and older mothers. Adolescence, 20, 805-822.

Siegel, L.S. (1982). Reproductive, perinatal, and environmental variables as predictors of development of preterm ( $<1500$ grams) and fullterm children at 5 years. Seminars in Perinatology, 6, 274-279.
Siegel, L.S. (1983). The prediction of possible learning disabilities in preterm and fullterm children. In T. Field \& A. Sostek (Eds.), Infants born at risk: Physiological and perceptual processes (pp. 295-315).

Sigel, I.E. (1984). The relationship between parental distancing strategies and the child's cognitive behavior. In M.E. Lamb, A.L. Brown, $\varepsilon$ B. Rogoff, (Eds.), Advances in Developmental Psychology (Vol. 3, pp. 47-86). Hillsdale, NJ: Lawrence Erlbaum.

Sigel, I.E. (1985). A conceptual analysis of beliefs. In I.E. Sigel (Ed.), Parental belief systems: Psychological consequences for children (pp. 345-371). Hillsdale, NJ: Lawrence Erlbaum.

Stevens, J.H. (1984). Child development knowledge and parenting skills. Family Relations, 33, 237-244.

This study was supported in part by a grant from the National Institute of Disability and Rehabilitation Research, U.S. Department of Education. Requests for reprints should be sent to Samuel J. Meisels, Center for Human Growth and Development, The University of Michigan, 300 N. Ingalls, Ann Arbor, MI 48109.

Address correspondence to Margo Dichtelmiller, Center for Human Growth and Development, University of Michigan, 300 North Ingalls, Ann Arbor, MI 48109. 